\title{
Consequences of the thermal transient on the evolution of the damaged zone around a repository for heat-emitting high-level radioactive waste in a clay formation: a performance assessment perspective
}

$\mathrm{Li} \mathrm{Yu}^{\mathrm{a}}$, Eef Weetjens ${ }^{\mathrm{a}}$, Xavier Sillen ${ }^{\mathrm{b}}$, Tim Vietor ${ }^{\mathrm{c}}$, Xiangling Li ${ }^{\mathrm{d}}$, Pierre Delage $^{\mathrm{e}}$, Vincent Labiouse ${ }^{\mathrm{f}}$, Robert Charlier ${ }^{\mathrm{g}}$

\footnotetext{
${ }^{a}$ Belgian Nuclear Research Centre (SCK•CEN), Institute for Environment, Health and Safety, Boeretang 200, B-2400 Mol, Belgium

${ }^{b}$ Belgian Agency for Radioactive Waste and Enriched Fissile Materials (ONDRAF/NIRAS), Avenue des Arts 14, B-1210 Brussels, Belgium

${ }^{c}$ National Cooperative for the Disposal of Radioactive Waste (NAGRA), Hardstrasse 73, 5430 Wettingen, Switzerland

${ }^{d}$ European Underground Research Infrastructure for Disposal of Nuclear Waste in Clay Environment (EURIDICE), B-2400 Mol, Belgium

${ }^{e}$ Ecole des Ponts Paris Tech, UR Navier/CERMES, F 77455 Paris, France

${ }^{f}$ Rock Mechanics Laboratory, Ecole Polytechnique Fédérale de Lausanne, station 18, CH1015 Lausanne, Switzerland

${ }^{g}$ Department GeomaC, University of Liege, Sart Tilman B52/3, Chemin des Chevreuils 1, B4000 Liege, Belgium
}

This is the accepted author's version of an article protected by copyright.

The rights are held by Springer-Verlag Wien.

The final publication is available at http://link.springer.com.

http://link.springer.com/article/10.1007/s00603-013-0409-4

Article published in:

Rock Mechanics and Rock Engineering (ISSN 0723-2632)

Special issue: Thermo-hydro-mechanical effects in clay host rocks

edited by Jean Sulem and Xiang Ling Li

Digital Object Identifier (DOI): DOI 10.1007/s00603-013-0409-4 


\title{
Consequences of the thermal transient on the evolution of the damaged zone around a repository for heat-emitting high-level radioactive waste in a clay formation: a performance assessment perspective
}

Li Yu ${ }^{a}{ }^{*}$ Eef Weetjens ${ }^{a}$, Xavier Sillen ${ }^{b}$, Tim Vietor ${ }^{c}$, Xiangling Li ${ }^{d}$, Pierre Delage ${ }^{\mathrm{e}}$, Vincent Labiouse ${ }^{\mathrm{f}}$, Robert Charlier ${ }^{\mathrm{g}}$

\footnotetext{
${ }^{a}$ Belgian Nuclear Research Centre (SCK•CEN), Institute for Environment, Health and Safety, Boeretang 200, B-2400 Mol, Belgium

${ }^{b}$ Belgian Agency for Radioactive Waste and Enriched Fissile Materials (ONDRAF/NIRAS), Avenue des Arts 14, B-1210 Brussels, Belgium

${ }^{c}$ National Cooperative for the Disposal of Radioactive Waste (NAGRA), Hardstrasse 73, 5430 Wettingen, Switzerland

${ }^{d}$ European Underground Research Infrastructure for Disposal of Nuclear Waste in Clay Environment (EURIDICE), B-2400 Mol, Belgium

${ }^{e}$ Ecole des Ponts Paris Tech, UR Navier/CERMES, F 77455 Paris, France

${ }^{f}$ Rock Mechanics Laboratory, Ecole Polytechnique Fédérale de Lausanne, station 18, CH-1015 Lausanne, Switzerland

${ }^{g}$ Department GeomaC, University of Liege, Sart Tilman B52/3, Chemin des Chevreuils 1, B-4000 Liege, Belgium
}

*Corresponding author. Tel.: (32)14 333237; fax: (32)14 323553.

Postal address: Boeretang 200, SCK•CEN, 2400 Mol, Belgium

\author{
E-mail addresses: 1yu@sckcen.be (Li Yu) \\ eweetjen@sckcen.be (Eef Weetjens) \\ x.sillen@nirond.be (Xavier Sillen) \\ tim.vietor@nagra.ch (Tim Vietor) \\ xli@sckcen.be (Xiangling Li) \\ delage@cermes.enpc.fr (Pierre Delage) \\ vincent.Labiouse@epfl.ch (Vincent Labiouse) \\ Robert.Charlier@ulg.ac.be (Robert Charlier)
}


Abstract: A proper evaluation of the perturbations of the host rock induced by the excavation and the emplacement of exothermic wastes is essential for the assessment of the long-term safety of high-level radioactive waste disposals in clay formations. The impact of the thermal transient on the evolution of the damaged zone (DZ) has been explored in the European Commission project TIMODAZ (Thermal Impact on the Damaged Zone Around a Radioactive Waste Disposal in Clay Host Rocks, 2006 - 2010). This paper integrates the scientific results of the TIMODAZ project from a performance assessment (PA) point of view, showing how these results support and justify key PA assumptions and the values of PA model parameters. This paper also contextualises the significance of the thermal impact on the DZ from a safety case perspective, highlighting how the project outcomes result into an improved understanding of the ThermoHydro-Mechanical behaviour of the clay host rocks.

The results obtained in the TIMODAZ project strengthen the assessment basis of the safety evaluation of the current repository designs. There was no evidence throughout the TIMODAZ experimental observations of a temperature-induced additional opening of fractures nor of a significant permeability increase of the DZ. Instead, thermally-induced plasticity, swelling and creep seem to be beneficial to the sealing of fractures and to the recovery of a very low permeability in the DZ, close to that of an undisturbed clay host rock.

Results from the TIMODAZ project indicate that the favourable properties of the clay host rock, which guarantee the effectiveness of the safety functions of the repository system, are expected to be maintained after the heating-cooling cycle. Hence, the basic assumptions usually made in PA calculations so far are expected to remain valid, and the performance of the system should not be affected in a negative way by the thermal evolution of the $\mathrm{DZ}$ around a radioactive waste repository in clay host rock.

Keywords: clay host rock; DZ (damaged zone); thermal impact; disposal safety; performance assessment. 


\section{Introduction}

According to the International Atomic Energy Agency (IAEA), the fundamental objective of any radioactive waste management activity is "to protect people and the environment from harmful effects of ionizing radiation" (IAEA 2006). Waste disposal, that is emplacement of waste produced by our generation in an appropriate facility, is the main internationally accepted way to provide such a protection without imposing undue burdens on future generations (ICRP 2000). The generally adopted strategy consists in concentrating and confining the radioactive wastes and in isolating them from man and the environment. Geological disposal, that is disposal in a repository constructed in a stable geological formation, is a promising solution recommended at international level for high-level waste (HLW) and intermediate-level waste (ILW) (NEA 1995; IAEA 2006b). It employs an engineered barrier system (EBS) and the natural barrier (the host rock) between the contaminants and the accessible biosphere, in order to prevent radionuclides and other contaminants ever reaching concentration at which they could present an unacceptable risk for man and the environment.

Argillaceous formations have been under consideration in many countries for decades as potential host rock for high-level radioactive waste repositories. The Belgian Agency for Radioactive Waste and Enriched Fissile Materials (ONDRAF/NIRAS) is assessing the feasibility of disposing vitrified high-level waste (VHLW) and spent fuel (SF) together with long-lived low- and/or intermediate-level waste (LL-ILW) in a geological repository excavated in the Boom Clay (ONDRAF/NIRAS 1989 and 2001; Bel et al. 2005). IAEA (2006b) imposes that the engineered barriers should be designed to provide complete containment of the heat-generating waste at least throughout the thermal phase to avoid coping with complex behaviours of radionuclide transport during this period. In the Belgian concept, heat-emitting waste (VHLW \& SF) packages are placed in so-called supercontainers consisting of a carbon steel overpack embedded in a concrete buffer. This buffer provides radiological shielding for underground operations and a favourable geochemical environment for minimising corrosion. The Swiss 
National Cooperative for the Disposal of Radioactive Waste (NAGRA) has assessed the feasibility of setting a repository for HLW, SF and LL-ILW in the Opalinus clay in northern Switzerland. Containment of the heat emitting waste is ensured by a thick carbon steel canister surrounded by a bentonite clay backfill (NAGRA 2002a and 2002b).

According to the international practice, the development and implementation of a geological repository are planned in a cautious, stepwise process, punctuated by the submission to the government of key documents marking the end of successive "programme stages". The socalled "safety and feasibility cases" are submitted in support of decisions to be requested (NEA 2004 and 2007). A safety and feasibility case is a synthesis of evidence, analyses and arguments to quantify and substantiate that a repository will be safe after closure and beyond the time when active control of the facility can be relied upon. Demonstrating good knowledge and sufficient understanding of the expected phenomenological evolution of the disposal system is an essential element of the case, as well as a clear indication of the remaining uncertainties, their significance in the context of the decision at hand and guidance for work to resolve them if necessary.

Performance assessments of geological disposal systems in clay formations have repeatedly highlighted the role of the clay as the dominant barrier delaying and attenuating radionuclide releases to the environment once full containment by the EBS cannot be relied upon anymore. As a side effect of radioactive decay, VHLW and SF release a significant amount of heat, even after several decades of cooling in surface facilities, and this will perturb the clay host rock. The temperature evolution in the near field of a supercontainer-based repository filled with VHLW is illustrated in Figure 1 (Weetjens 2009). In agreement with the IAEA requirement, the EBS is designed to ensure complete containment of radionuclides in metal overpacks at least during the thermal phase, i.e. the period of time during which the temperature of the host formation lies above the range of temperatures within which typical migration properties can be relied upon (ONDRAF/NIRAS 2009c). As the overpacks eventually fail at some time during the 
post-thermal phase, the safety of the system will mainly rely on the barrier capabilities of the host formation.

Excavation, construction and operation of the repository and the emplacement of heatemitting radioactive waste will inevitably induce mechanical $(\mathrm{M})$, hydraulic $(\mathrm{H})$, thermal $(\mathrm{T})$, and chemical (C) perturbations to the surrounding clay host rocks and create a disturbed zone (Bernier et al. 2006). Within the disturbed zone lies the so-called Excavation Damaged Zone (EDZ) created around the shafts and galleries during the excavation processes. The damaged zone (DZ) is defined as the zone in which hydro-mechanical and geochemical modifications induce significant changes in flow and transport properties (Bernier et al. 2006), i.e. along which water and solutes mobility could be enhanced. In the European Commission (EC) project SELFRAC (2002 - 2006), the EDZ and its evolution with time has been characterised and its impact on the performance of radioactive waste geological repositories has been assessed (Bernier et al. 2006). However, the influence of the thermal load generated by the radioactive waste on the evolution of the EDZ was not studied in the frame of SELFRAC. Since the heatinduced Thermo-Hydro-Mechanical (THM) perturbations on the clay host rock might well be the most severe disturbance that the repository system will undergo, the consequence of the thermal transient on the EDZ evolution as well as the possible additional damage created by the thermal load and its impact on the safety-relevant properties of the clay host rock need to be thoroughly investigated.

Following SELFRAC, the European TIMODAZ project (Thermal Impact on the Damaged Zone Around a Radioactive Waste Disposal in Clay Host Rocks, 2006 - 2010) involved research centres, academia, radioactive waste management organisations and regulators, especially was designed to tackle the key research issues associated with the thermal impact on the evolution of the damaged zone (DZ) in the clay host rocks around a radioactive waste repository. Beyond the characterisation of the initial damage induced by the excavations, the extent and the hydro-mechanical behaviour of the DZ during different repository evolution 
stages (including the operational period and thermal and post-thermal post-closure stages) were investigated. The main objectives of the TIMODAZ project were to gather knowledge to support the assessment of the significance of the thermal effects in the safety evaluations and to provide direct feedback to repository design teams. As such, the TIMODAZ results should help to establish a sound scientific and technical basis for demonstrating the feasibility and safety of geological disposal.

The present paper integrates from a performance assessment (PA) point of view the main scientific and technical outputs obtained within the framework of the TIMODAZ project. It firstly summarizes the results and observations from small- to medium-scale laboratory and in situ tests performed within the TIMODAZ project. These results contribute to a better understanding of the processes occurring within the clay around a disposal system of heatemitting waste during the thermal transient phase. It thus strengthens the quality and reliability of the assessment basis for the safety evaluations. Three types of clay, the Boom Clay, the Opalinus Clay and the Callovo-Oxfordian Claystone, considered as possible clay host rock in Belgium, Switzerland and France respectively, were investigated during the project. In this paper, the emphasis lies on the first two clays. The knowledge gained is afterwards used for the assessment of the safety-relevant properties of the clay host rocks, and the role of the DZ within a safety case for radioactive waste disposal in clay formations is discussed. Finally, some recommendations to the Belgian and Swiss repository design and operation are formulated.

\section{Improved understanding of Thermo-Hydro-Mechanical behaviour of clay}

A good comprehension of the inter-related processes occurring within the clay around a disposal system for heat-emitting waste, specifically the evolution of the DZ during the thermal transient, is essential to gain confidence in PA. Beyond the understanding of the general DZ evolution, the possible alteration of some favourable clay properties relevant to the disposal safety is of specific interest. Such properties include a very low permeability, the absence of 
preferential migration pathways for solutes, high radionuclides retention capacity as well as swelling and creep properties that result in a good self-sealing capacity. Together, these properties make clay host rock very efficient at delaying and attenuating radionuclides release from waste packages to the accessible biosphere, and thus provide robustness to the disposal system.

Numerous laboratory and in situ tests have been designed and conducted in the TIMODAZ project. They are aimed to improve the understanding of coupled processes occurring during the thermal phase within the clay formation around a geological repository. Key results, which strengthen the scientific basis for evaluating repository performance and safety in clay formations, are presented hereafter.

\subsection{Strong Thermo-Hydro-Mechanical coupling}

An important thermally-induced effect in low permeability media such as clays and claystones is the pore water pressurization that occurs upon heating (Delage et al. 2010; Mohajerani et al. 2012). Such strong THM couplings were clearly demonstrated from both in situ experiments and laboratory tests performed in the TIMODAZ project.

Two in situ small-scale heater tests were conducted in TIMODAZ, i.e. SE-H at the Mont Terri Underground Research Laboratory (URL) (Switzerland) and ATLAS III at the HADES Underground Research Facility (URF) (Mol, Belgium). Measurements of temperature and pore water pressure from these two tests provided further evidences about the strong THM couplings in clays. As an example, some observations in ATLAS III in the Boom Clay are presented here (Chen et al. 2011). The layout of the boreholes, together with the changes in pore water pressure with temperature measured at the end of borehole AT93E, is shown in Figure 2. Borehole AT93E is located at about $1.3 \mathrm{~m}$ to the left of the heater borehole. The heater power was increased in three steps. After each increase, the power was maintained constant along a given period of time ( 45 days at $400 \mathrm{~W}, 66$ days at $900 \mathrm{~W}$ and 256 days at $1400 \mathrm{~W}$ ).. 
As seen in Figure 2, a rapid increase in pore water pressure is induced at the beginning of each heating step, followed by stabilisation. During the longer step at $1400 \mathrm{~W}$, one can observe afterwards a continuous decrease even when temperature keeps increasing (e.g., from Oct. 2007 on). The temperature rise generates excess pore water pressure within saturated clays due to the significantly larger thermal expansion coefficient of water compared to that of solids. Thermal consolidation (studied in the Boom Clay by Delage et al. 2000) simultaneously occurs with excess pore water pressure dissipating towards the far field. In low permeability clays like the Boom Clay, heat transfer is significantly faster than water transfer. The slower water dissipation rate allows for a sharp initial increase in pore water pressure at the beginning of each heating phase (the temporary and small decrease in pore water pressure observed at the very beginning of each heating phase will be commented specifically in section 2.4.3). After a sufficiently long period of time $(\sim 2$ months), the pore pressure dissipation rate overcomes the thermal pressurization rate, resulting in a decrease in pore water pressure. The magnitude of the excess pore pressure thus not only depends on the temperature increase, it is also very sensitive to the temperature increase rate (Picard and Giraud 1995) and to the hydraulic diffusivity. As the thermal diffusivities of both clays are of the same order of magnitude, the pore pressure response to a given thermal load will thus be sharper in the less permeable and stiffer Opalinus Clay than in the Boom Clay.

\subsection{Thermally-induced plasticity}

The thermal behaviour of the Boom Clay is characterized by non-linear and irreversible volume changes that significantly depend on the overconsolidation ratio. Overconsolidated samples submitted to a slow temperature elevation in drained conditions (no pore water pressure changes) first exhibit a thermal reversible dilation followed by an irreversible plastic contraction (Baldi et al. 1991; Sultan et al. 2000). The temperature at which occurs the transition between 
dilation and compaction increases with the overconsolidation ratio. The cooling slope is parallel to the slope of the dilation heating phase (Sultan 1997; Sultan et al. 2002).

Drained heating tests (heating rate $1{ }^{\circ} \mathrm{C} / \mathrm{h}$ ) under constant stress close to in situ conditions (mean stress 4.1 MPa and back pressure 2.2 $\mathrm{MPa}$ ) have been conducted in TIMODAZ at ENPC/CERMES (École des Ponts ParisTech, France) to investigate the thermal behaviour of Opalinus clay (Monfared et al. 2012a). To improve saturation, drainage and the pore pressure field homogeneity, this group developed an original hollow cylinder triaxial apparatus characterized by a reduced drainage length $(10 \mathrm{~mm})$ (Monfared et al. 2011). As seen in Figure 3, thermal volume change under drained heating is characterized by an initial thermoelastic dilation between $25^{\circ} \mathrm{C}$ and $65^{\circ} \mathrm{C}$ followed by a plastic contraction between $65^{\circ} \mathrm{C}$ and $83^{\circ} \mathrm{C}$ and an elastic contraction upon cooling. A second temperature cycle evidenced a thermoelastic dilation up to $80^{\circ} \mathrm{C}$ followed by a thermoelastic contraction during cooling. Irreversible volumetric contraction strains of $0.4 \%$ and $0.12 \%$ were observed at the end of each cooling phase, respectively.

This response is typical of thermoplastic hardening behaviour: heating a clay previously submitted to temperature elevation results in thermoelastic dilation up to the maximum temperature previously undergone. Plastic contraction occurs at higher temperature. This is observed during the first cycle, given that the maximum undergone temperature by the Opalinus Clay during geological history is estimated around $70^{\circ} \mathrm{C}$. When this temperature is exceeded during the first cycle up to $85^{\circ} \mathrm{C}$, contraction occurs. A second temperature cycle exhibits thermoelastic dilation up to $85^{\circ} \mathrm{C}$, illustrating remarkably the thermal hardening effect.

\subsection{Alterations of the water retention capacity}

The changes in the water retention properties of the Opalinus Clay and Boom Clay with temperature were investigated at LMS-EPFL (Soil Mechanics Laboratory, Ecole Polytechnique Fédérale de Lausanne) by determining the water retention curves at ambient temperature and at $80^{\circ} \mathrm{C}$ (Laloui et al. submitted; Rizzi 2013). Due to the surface tension decreases with 
temperature, the elevated temperature thus reduces the water retention capacity of the clay. In other words, at a given suction (above the air entry value), the degree of water saturation (and/or the water content) decreases with increasing temperature. As seen in Figure 4, the water retention curve shifts leftwards at elevated temperature and the air entry value of the Boom Clay decreases from $3 \mathrm{MPa}$ at ambient temperature to less than $1 \mathrm{MPa}$ at $80^{\circ} \mathrm{C}$.

\subsection{Anisotropic properties}

Most sedimentary formations are characterized by some degree of anisotropy. Several tests performed during the TIMODAZ project evidenced anisotropic behaviours and sometimes allowed to quantify in situ anisotropic properties of the clay. Numerical modelling carried out in TIMODAZ by various groups also confirmed that including anisotropies generally improved the calculation results and allowed the capture of some very specific features of the behaviour revealed by the tests. The effects of initial in situ stress anisotropy and of the anisotropic hydraulic conductivity have been already investigated in the SELFRAC project. These were found to explain for instance the anisotropic pore pressure distribution measured around the connecting gallery at HADES URL (Bernier et al. 2006). Further investigation of the anisotropic hydraulic conductivity of the Boom Clay was conducted by Monfared et al. (2012b). In this paper, we will focus on the thermal and mechanical anisotropy.

\subsubsection{Thermal anisotropy}

The spatial distribution of the temperature sensors installed in the ATLAS III in situ experiment allowed quantifying the in situ anisotropy of the thermal conductivity of the Boom Clay. The measured temperature evolutions at various positions are illustrated in Figure 5 (solid line) by four temperature sensors. Three of them are parallel to bedding and one is perpendicular to bedding. Numerical analysis results (dashed line in Figure 5) gives very good agreements with spatial temperature measurements by adopting anisotropic thermal conductivity values of 
about $1.65 \mathrm{~W} /(\mathrm{m} \cdot \mathrm{K})$ along the bedding plane and $1.31 \mathrm{~W} /(\mathrm{m} \cdot \mathrm{K})$ perpendicular to the bedding plane (Chen et al. 2011).

\subsubsection{Mechanical anisotropy and its role in the creation and evolution of the damaged zone}

In situ investigation has been performed in the Mont Terri URL around a borehole that follows the bedding strike of the Opalinus Clay. After injecting a fluorescent resin and overcoring afterwards the injected borehole, sections of the core were saw-cut to study the damage around the borehole. As seen in Figure 6(a), the resin trace image presents a buckling fracture mode controlled by the bedding orientation (Labiouse and Vietor 2013). The removal of the dilatometer probe completely unloaded the borehole wall and the borehole collapsed. The original borehole is represented by the elliptical opening in the centre of the overcored slice. Inspection of the entire set of slices showed that the geometry and extent of the elliptical opening

result from a larger convergence in the direction normal to bedding than parallel to bedding. A sketch of the borehole collapse pattern is given in Figure 6(b). This collapse structure demonstrates that the deformation and failure of the clay is controlled by the bedding. Also, the EDZ shape appears to be controlled by the orientation of the opening with respect to the bedding.

A similar fracture pattern around the central hole was observed in the medium-scale hollow cylinder laboratory test $\mathrm{N}^{\circ} 12$ on the Opalinus Clay performed at LMR-EPFL. As seen in Figure 6(c), cracks sub-parallel to the bedding plane opened, leading to a buckling failure in two areas that extend from the borehole in the direction normal to bedding (Labiouse and Vietor 2013). Another similar fracture pattern was found at large-scale around a gallery at Mont Terri URL as shown in Figure 6(d). On the roof of the tunnel, obvious buckling developed parallel to bedding, resulting in a larger extent of the EDZ wain the direction perpendicular to bedding.

The consistency among experiments carried out over various scales provides good confidence about upscaling laboratory tests to repository-scale tests. However, any upscaling 
should take into account the differences in experimental procedures at different scales (rates and techniques of excavation, application of support).

Contrary to the Opalinus Clay, a larger convergence of the central hole occurred in the direction parallel to the bedding plane in the hollow-cylinder tests carried out on the Boom Clay at LMR-EPFL (Figure 7(a)) (Labiouse et al. 2013). Total displacement profiles are plotted along diameters parallel, perpendicular and at $45^{\circ}$ with respect to the bedding planes by tracking the displacement of pyrite inclusions in the X-ray CT scans performed before and after mechanical unloading (Figure 7(b)). The convergence around the central hole is clearly larger along bedding than normal to bedding. Based on the displacement profiles, a "damaged" zone can be delimited visually around the central hole. This zone is roughly an ellipse, with a major axis oriented along the bedding plane.

The anisotropic deformation pattern is consistent with that inferred from measurements recorded during the construction of the PRACLAY gallery of the HADES URF (Van Marcke and Bastiaens 2010). The PRACLAY gallery is a horizontal drift with a length of about $45 \mathrm{~m}$ and an external diameter of $2.5 \mathrm{~m}$. It was constructed in 2007 in the Boom Clay at a depth of 223 m perpendicular to the already existing Connecting gallery (constructed in 2002 with a length of $85 \mathrm{~m}$ and external diameter of $4.8 \mathrm{~m}$, Bastiaens and Demarche 2003). A crossing was installed at the intersection between the two galleries. The PRACLAY gallery was excavated using an openface tunnelling machine at a rate of $2 \mathrm{~m} /$ day. An overexcavation was imposed (by adjusting the position of the cutting heads of the excavation shield) to limit on the one hand the friction on the tunnelling machine and to compensate for the convergence of the clay to reach the desired gallery diameter. On the other hand, the overexcavation was optimised to limit the total convergence of the clay and thus the damage to the host-rock. In practice, an overexcavation of $55 \mathrm{~mm}$ on diameter in vertical direction and of $81 \mathrm{~mm}$ in horizontal direction were needed to obtain the desired gallery profile due to smaller vertical convergence. Similarly, a larger convergence along the bedding plane was also observed during the excavation of the Connecting 
gallery (Van Marcke and Bastiaens 2010). Furthermore, the fracture pattern observed around the PRACLAY gallery appeared to be quite similar to that observed when excavating the Connecting Gallery as illustrated in Figure 7(c) (Blümling et al. 2007; Bastiaens et al. 2008). It consists of conjugated curved fracture surfaces with a curving more pronounced vertically than horizontally. The EDZ is thus not axisymmetrical with respect to the gallery axis, having a larger extent in the horizontal direction (parallel to the bedding plane).

The similar elliptic extent in the radial direction of EDZ observed around boreholes in hollow cylinder tests and around full-sized galleries suggests that, at least for those cases, the intrinsic clay behaviour is playing a larger role than the unloading path or excavation technique in the creation of these fracture patterns.

Both Boom Clay and Opalinus Clay are transversely isotropic materials with smaller stiffness in the direction perpendicular to bedding. The difference in exhibited damage pattern most probably results from different failure modes: ductile behaviour in the Boom Clay (i.e. shear failure prevails along conjugated planes) and brittle behaviour in the Opalinus Clay (tensile failure along bedding planes and buckling) (Labiouse and Vietor 2013). Accounting for mechanical anisotropy and plasticity in the simulation of the hollow-cylinder tests on the Boom Clay enables a correct modelling of the convergence pattern (François et al. 2013).

\subsubsection{Coupling between thermal loading and anisotropic mechanical behaviour}

Inspecting Figure 2 in more detail, one clearly observes that a temporary and small decrease in pore water pressure was systematically measured at the very beginning of each stepwise increase of heater power, whereas a short increase in pore water pressure occurred very quickly after the heater was turned off (Chen et al. 2011). The same phenomena have been observed in other sensors located in the horizontal direction from the heater, while the opposite has been observed for sensors located above the heater (the latter was indeed predicted, based on the TIMODAZ results). 
The delay observed in temperature changes with respect to changes in heater power is obviously related to the distance between the sensors and the heater, the thermal conductivity and heat capacity of the clay. Accordingly, one can observe in Figure 2 that once the power is switched off, temperature slightly keeps on increasing prior to decreasing while a peak in pore pressure is observed prior to the dissipation phase.

The physical explanation of the a priori unexpected response in pore pressure is not straightforward but numerical calculations accounting for hydromechanical couplings showed that they could be obtained quite easily by taking into account the anisotropy of the elastic parameters of the clay (Chen et al. 2011; Garitte et al. 2009). Such a simple constitutive model can be used here because the geometry of the ATLAS III experiment and the limited applied thermal load result in small deformations as far as the observation boreholes are concerned (most of them are beyond a few metres from the heater).

Although pore water pressure changes are of minor importance for PA, modelling studies that successfully account for a specific new feature (i.e. anisotropy) demonstrate an improvement in process understanding that helps build better confidence in the prediction of the behaviour of the whole system. The modelling contributions of TIMODAZ demonstrated the capability of numerical models to fairly well predict the strongly coupled effects due to temperature increase both in the damaged and in the intact rock (Garitte et al. 2009; Charlier 2010). Numerical models can support (or are consistent with) the current understanding of the various processes involved in the repository.

\subsection{Consequence of the pre-existing discontinuities in clay samples}

The TIMODAZ project significantly benefited from X-ray computed microtomography $(\mu \mathrm{CT})$, a non-destructive technique that allows the visualization of cracks and discontinuities in clay samples before, during and after testing. $\mu \mathrm{CT}$ indeed showed that pre-existing discontinuities on so-called "intact" samples appeared to be quite significant. Figure 8 shows one 
example of cracks observed at Laboratory 3SR in Grenoble in an Opalinus Clay specimen before testing. The image reveals a set of fissures parallel to bedding.

$\mu \mathrm{CT}$ observations confirmed that the processes of recovery, storage, transportation and trimming of clay samples indeed induce significant effects on samples. Further drying in ambient atmosphere allows the pre-existing fissures to grow noticeably in length and width. In order to minimize the impact of pre-existing damage, strict test protocols were defined at the beginning of TIMODAZ. It was recommended to resaturate specimens under confining stress and pore water pressure close to in situ mean values. These procedures significantly minimized the scattering of test results. The experimental data from the various research groups appeared to be quite consistent, hence substantially facilitating subsequent model calibration.

However, clays are natural materials and variability in their properties is unavoidable. An important consequence of the existence of pre-existing damage in clay samples before testing is that the calibrated parameters from lab tests may deviate from their in situ counterparts and should therefore be used with great caution in case they are applied to full size repositories (Delage 2010).

\section{Safety-relevant aspects of THM perturbation and evolution}

The geological formation around the disposal galleries is the dominant barrier for radionuclide transport in the multi-barrier system. It contributes to the long-term radiological safety of the disposal system by (1) limiting water flow through the system so as to ensure that the dominant radionuclide transport mechanism is diffusion; (2) retarding the migration of many radionuclides through physicochemical processes like sorption. These features ensure that most radionuclides will decay to negligible quantities within the host formation and that only a small fraction will eventually reach the biosphere. The fulfilment of these safety functions obviously depends on the preservation of the favourable properties of the clay. In this section, these safety- 
relevant aspects are evaluated to check if the clay host rock will still be able to fulfil its safety functions after experiencing severe THM perturbations.

\subsection{Maintenance of the very low permeability after the thermal loading}

Both the Boom Clay and Opalinus Clay are naturally low permeability clays with measured hydraulic conductivities in the order of $\sim 10^{-12} \mathrm{~m} / \mathrm{s}$ (Yu et al. 2013) and $\sim 10^{-12}-10^{-14}$ $\mathrm{m} / \mathrm{s}$ (Croisé et al. 2004), respectively. Because of the damage and decompression occurred in the clay after the excavation and construction of underground structures, an increase by a few orders of magnitude in hydraulic conductivity is initially observed in the EDZ. However, the SELFRAC project has shown that, as these clays have a self-sealing capacity, the EDZ hydraulic conductivity then tends to decrease towards the intact rock hydraulic conductivity, at formationdependent rates (Bernier et al. 2006).

In the isostatic tests (with constant and isotropic stress) carried out on Boom Clay and Opalinus Clay samples, the measured hydraulic conductivities increased during heating before recovering initial values after cooling. Figure 9 presents the data of an isostatic test carried out on the Boom Clay. The fairly constant intrinsic permeability detected at various temperatures confirmed that the increase in hydraulic conductivity with temperature was only due to the (reversible) decrease in water viscosity (Chen et al. 2013), as already shown in the Boom Clay by Delage et al. (2000).

Similar results were obtained in permeameter tests (with constant volume) on both intact and artificially damaged Boom Clay samples. Hydraulic conductivities of the clay samples were measured during a heating-cooling cycle (Figure 10(a)). The artificially damaged Boom Clay sample was obtained by cutting a previously saturated cylindrical core in two along its axis using a cutting wire. Afterwards, the two parts were put together and stayed in a permeameter cell without any further hydration (i.e. no additional water added). After less than one week, the fracture could not be visualized anymore by $\mu \mathrm{CT}$ scanning. The density profile reconstructed 
from the CT pictures also did not show any clear density decrease along the original fracture. Permeability measurements showed that the initial value of hydraulic conductivity was recovered. During a subsequent heating up to $80^{\circ} \mathrm{C}$, the intrinsic permeability of both intact samples and samples with artificial fractures remained constant. This suggests that the pore structure of the clay matrix was not affected by the temperature increase. Similar tests carried out with cement water (representative of the near field pore water composition of a repository with concrete barriers and cementitious backfill) showed that pore water chemistry had little influence on the permeability of the Boom Clay (Chen et al. 2013).

In the similar permeameter tests on Opalinus Clay specimens with artificial fractures, the hydraulic conductivity measured at the start of the test was still two orders of magnitude higher than the "intact" value. Unlike Boom Clay, a decrease in intrinsic permeability (Figure 10 (b)) was observed with the increasing temperature (Chen et al. 2013). The same phenomenon was also observed in the Mont Terri in situ SE-H heater test (Vietor et al. 2010) in which the intrinsic permeability showed a continuous decrease by a factor of about 4 when the temperature at the measurement point increased from $15.1^{\circ} \mathrm{C}$ to $65.3^{\circ} \mathrm{C}$.

In addition to the fractures created on purpose, $\mu \mathrm{CT}$ observations evidenced pre-existing fissures in many clay samples that have been used in the experimental programme of TIMODAZ. Nevertheless, the permeability tests, independently carried out in various laboratories by using different approaches with different pore water compositions on intact, initially damaged, cut or sheared samples, all provided permeability values close to the initial value in the Boom Clay, or evolving towards the initial value in the Opalinus Clay after the thermal cycle (heating/cooling).

Additional evidence of the preservation of a low intrinsic permeability is provided by in situ heater experiments. The ATLAS III in situ test, for instance, was successfully modelled using a constant intrinsic permeability equal to that of undisturbed clay. 
Throughout the TIMODAZ project, no significant increase in intrinsic permeability during and after heating was observed. However, an increase of intrinsic permeability from $1 \times 10^{-19} \mathrm{~m}^{2}$ to $2 \times 10^{-16} \mathrm{~m}^{2}$ was observed in one drained shearing test on the Boom Clay performed at Laboratoire 3SR in Grenoble (Delage 2010). According to Viggiani and Bésuelle (2012), this can be explained by the reopening of pre-existing cracks under a low mean stress $\left(p^{\prime}=0.3 \mathrm{MPa}\right)$. Obviously, more efforts are needed to investigate this phenomenon, even though in the repository system, such a low mean stress level is unlikely or avoidable by a suitable repository design and by managing construction and operation phases.

\subsection{Maintenance of the self-sealing capacity after the thermal loading}

Good sealing capacity is an important feature of a geological barrier material as it helps to limit the formation and propagation of preferential pathways even after various perturbations, thereby maintaining a low permeability. Throughout the TIMODAZ project, no negative impacts of a thermal transient on the sealing capacity of clay were found.

Sealing was clearly demonstrated for all the damaged Boom Clay samples in the permeameter and isostatic tests (Chen et al. 2013). The sealing rate appeared to be fast: sealing of the fractured Boom Clay samples occurred within a few days in the permeameter cells. In an isostatic cell, an artificial central hole of $6 \mathrm{~mm}$ in diameter in a Boom Clay sample sealed after the sample was consolidated at the relatively low effective pressure of $0.3 \mathrm{MPa}$. Regarding the effectiveness of the sealing, the measured intrinsic permeabilities under different temperatures in permeameter test and at mean effective stress of $2.25 \mathrm{MPa}$ in isostatic test are comparable to in situ measurements in undisturbed Boom clay. Neither negative nor positive thermal impacts on the sealing of the damaged Boom Clay samples were observed from the tests.

Although the sealing rate was much slower for the fractured Opalinus Clay samples tested in the permeameter cell, a temperature increase has a favourable impact on the sealing 
behaviour. After hydration and heating in the permeameter cells, the intrinsic permeability decreased to the in situ measured value in non-damaged Opalinus Clay. Under isostatic test condition, after hydration, consolidation and heating for more than 8 months, previously drilled $2 \mathrm{~mm}$-diameter holes were however still present in artificially damaged Opalinus Clay samples.

Clearly, the set of test results gathered within the TIMODAZ project indicates that sealing is not hindered and the previously sealed fractures are not reopened at the temperatures expected around a disposal system or during the subsequent cooling, as long as the clay is subjected to some compressive stresses. This is normally the case around a repository and should be further demonstrated by the large-scale heater tests. These large-scale heater tests mimic in situ realistic disposal configurations. In order to confirm that the minimum effective stress remains compressive in the EDZ during the thermal phase, i.e. no thermal pressurization-induced hydro-fracturing will take place, the large-scale heater tests will be complemented by numerical simulations performed at the relevant scale, representing the boundary conditions imposed by the disposal system.

One should note that while many evidences of sealing have been collected throughout the TIMODAZ project, no indication of healing was obtained. On the contrary, the reappearance of the fractures or holes in the samples after dismantling confirms the observation from the SELFRAC project that the original mechanical properties cannot be recovered even after a heating-cooling cycle. In other words, while the fracture network is effectively closed from a hydraulic point of view, it is still present. In a specially designed apparatus, the thermomechanical failure of a sheared Boom Clay sample was studied (Monfared et al. 2012b). During an undrained heating test under constant shear and total volumetric stresses, a shear band previously created at ambient temperature was reactivated because of the thermal pressurization of the pore water. While the existing shear band behaved as a preferential plane for thermo- 
mechanical failure, it was not found to significantly affect the permeability of the clay sample at low or high temperatures.

\subsection{No significant impacts on major clay mineral, cation exchange capacity and specific surface}

The equilibrium state and rates of geochemical reactions change with temperature. Elevated temperatures increase the solubility of most solids, decrease the solubility of most gases and increase most reaction rates. Thermally induced geochemical reactions, consisting of ion exchange and mineral dissolution and precipitation, could have some effects on the chemistry of pore water and/or the stability of minerals. Thermal effects on clay minerals and organic materials - if present - are most prominent in argillaceous formations. These processes should be evaluated to assess the effects of a temperature increase on the retardation, sorption, pore structure, and matrix diffusion properties of the host rock (Mazurek et al. 2003).

One-year batch experiments carried out on Boom Clay and Opalinus Clay samples exposed to $90{ }^{\circ} \mathrm{C}$ suggested that the clay mineralogical composition was not significantly affected by temperature when in contact with both in situ pore water and geochemically disturbed pore waters representative of various possible chemical conditions around a repository (Honty et al. 2012). Precipitation of calcite in the Boom Clay was observed as a result of temperature increase. Key properties linked to radionuclide retention such as cation exchange capacity and total surface area were not affected in the course of a one-year experiment at $90^{\circ} \mathrm{C}$. Also in the Boom Clay, both experiments and modelling indicated that, due to the thermal degradation of natural organic matter, the temperature increase reduced the $\mathrm{pH}$ and increased the partial pressure of $\mathrm{CO}_{2}$ in the pore water. While the effect of thermally-induced changes of pore water chemistry falls outside of the scope of TIMODAZ and the role of organic matter is rather specific to the organic-rich immature Boom Clay, this drop in $\mathrm{pH}$ and the increase in partial 
pressure of $\mathrm{CO}_{2}$ may have potential effects on the speciation and thus the retention of radionuclides. These effects should be assessed.

\section{Role of the damaged zone in performance assessment}

With the current knowledge, it is reasonably believed that the properties of the clay formations necessary to fulfil the safety functions of a repository system are still maintained in spite of the inevitable creation of an EDZ around the disposal galleries, as well as the thermal evolution of both EDZ and the "intact" rock due to the decay heat released by the vitrified highlevel wastes and the spent fuel. The remaining uncertainties regarding gas production (mostly due to the anaerobic corrosion of EBS metals in the case of high-level wastes) are currently under investigation in the EC project FORGE. The chemical perturbations in the clay formation have not been fully explored in TIMODAZ. Because of the complexity associated with reactive transport and the slow evolution of chemical perturbations, uncertainties related to the long timescales can partly be addressed by modelling and analogue investigations.

If the EBS behaves as designed in the reference scenario (i.e. the normal expected evolution), the radionuclides migration and thus the long-term radiological consequences in PA calculations are determined by the post-thermal state of the clay formation (including the damaged zone) after the heating-cooling cycle. Through the rigorous identification of the processes and phenomena that can be neglected in the PA analysis, the calculation of radionuclides transport within a repository system can be significantly simplified by adopting the following hypotheses/assumptions. The validity of these hypotheses/assumptions needs to be checked for clay formations that experienced a thermal transient.

o A limited DZ extent: the DZ extent determines the thickness of the effective clay barrier that may be relied upon in the performance assessment. Although shear band reactivation has been observed in undrained conditions due to thermal pressurization of the pore water, 
and a thermo-plastic contracting behaviour of the clay has been observed in drained conditions, no significant increase of permeability was observed. Thermal loading of the clay did not induce opening of fractures in any of the TIMODAZ experiments. Modelling exercises also suggest that the opening of fractures during the thermal phase is not to be expected. Large scale in situ heater tests mimicking actual repository conditions are about to start and need to confirm this;

o Recovery of the hydraulic conductivity in the DZ: TIMODAZ data demonstrated that the thermal transient has no negative impacts on the sealing capacity of the clays investigated. Instead, thermal-induced plasticity, swelling and creep are likely to be beneficial to the sealing of fractures and to the recovery of the DZ permeability back to its original state. In that sense, TIMODAZ results strengthen the conclusions of SELFRAC;

o Diffusion dominant transport in clay formations: in repositories located in low-permeability clay formations, and in the absence of substantial hydraulic gradients, diffusion is the dominant solute transport mechanism. Therefore, advective flux through the host formation can often be neglected in performance assessment models. Based on the observation that the intrinsic permeability (and hence the pore structure) of clays remained unchanged or even decreased with elevated temperature, TIMODAZ indicates that this assumption of dominant diffusive radionuclides transport still remains valid in clays after a thermal transient. TIMODAZ data further indicate that there is no significant change of the clay minerals after the heating-cooling cycle. Therefore, the pore diffusion coefficient of dissolved solutes is expected to remain unchanged. However, it should be noted that kinetics of precipitation/dissolution processes (with the potential to alter the clay structure) might be very slow and may therefore have remained undetected in the TIMODAZ oneyear batch tests. 
The diffusion and sorption properties of the geological formation around the repository are often considered to be homogeneous and isotropic in PA calculations. Findings from the TIMODAZ project clearly showed that clay formations show strong mechanical, hydraulic and thermal anisotropic behaviour with respect to bedding. It has been known for quite some time (De Cannière et al. 1996; Bruggeman et al. 2010) that solute diffusion coefficients and hydraulic conductivities are larger along the direction parallel to the bedding plane than along the perpendicular one. In situ heater experiments have shown that this also applies to the thermal conductivities. If the layers are sub-horizontal (which is likely for most possible sites), neglecting this effect for solute and water transport when evaluating radiological consequences of the repository system is conservative.

Although it was demonstrated in TIMODAZ that a temperature elevation has no negative effect on the sealing of fractures and on the recovery of the DZ permeability, whether the radionuclide transport properties of intact clay (in terms of sorption behaviour or apparent diffusion) can be used for the DZ is still an open issue. The oxidation occurring in the fractured zone during the operational phase and further geochemical perturbations that could be due to interactions with the EBS materials might lead to a possible alteration of the geochemical properties of the clay. However, the thermal impact on the geochemically disturbed zone was beyond the scope of the TIMODAZ project.

Both in situ data at Mont Terri and the $\mu \mathrm{CT}$ images of hollow cylinder obtained at EPFL for Opalinus Clay suggest that fractures in the EDZ are connected in the direction parallel to the hole or gallery axis. They may for instance act later as a path of less resistance for the gas evacuation. In the underground repository, gas would be inevitably produced by the degradation of the EBS components and the waste. When the gas production rate exceeds the capacity of the clay host rock to evacuate this gas by dissolution in the porewater and molecular diffusion alone, this discontinuity network may act as a gas evacuation pathway along the underground structures 
if the EBS itself does not provide a path of even lower resistance. This topic is currently being investigated in the EC FP7 project FORGE. However, the possible resulting water fluxes are believed to be very small due to the limitation of the water supply around the DZ because of the low permeability and the relative high air entry value of such clays (Bernier et al. 2006).

\section{Feedback to repository design}

\subsection{Feedback to the Belgian repository design}

In the Belgian repository design, a temperature limit is conservatively set at $100^{\circ} \mathrm{C}$ for the overpack (primary carbon steel barrier in the supercontainer concept) in order to preserve a passivation layer ensuring very low corrosion rates. Because the thermal load per metre gallery and the repository layout are optimised with respect to this constraint and to a limitation of the temperature increase at the top of the host rock not exceeding $10^{\circ} \mathrm{C}$ (ONFRAF/NIRAS 2001, 2008), peak temperatures in the $\mathrm{EDZ}$ will remain lower than $80^{\circ} \mathrm{C}$. As mentioned above, results from the TIMODAZ project showed that safety-relevant properties in the DZ such as a low permeability and good self-sealing capacity do not evolve in an unfavourable manner at an elevated temperature of $90{ }^{\circ} \mathrm{C}$ in the Boom Clay and are preserved after the thermal transient.

Additional knowledge gained during TIMODAZ about the anisotropy of thermal conductivity and of the mechanical properties of the Boom Clay may be used to further optimise the layout from a thermal point of view and possibly excavation technique.

Experimental results from TIMODAZ also provide further arguments for the use cementitious material in the repository. Sealing of artificial fractures in samples was observed to occur in constant volume conditions (permeameter cells). Hence, the self-sealing capacity of the Boom Clay is expected to be sufficient in the EDZ even though the concrete-based EBS will not actively recompress the clay as bentonite type of EBS. Furthermore, tests performed in 
TIMODAZ with evolved cement water suggest that the corresponding chemical perturbation should not alter the sealing capacity of the Boom Clay.

\subsection{Feedback to the Swiss repository design}

The Swiss design of geological repository for high-level waste foresees a spacing of $40 \mathrm{~m}$ between galleries. A variable canister pitch of 5 to $8 \mathrm{~m}$ together with careful calculations of heat emission will ensure homogeneous heat production along the gallery. Thermal calculations showed that the maximum temperatures reached at the inner surface of the EDZ are close to $80^{\circ} \mathrm{C}$ and will be reached within 10 years, corresponding to a temperature increase of approximately $40^{\circ} \mathrm{C}$. The TIMODAZ results showed that this temperature increase do not alter the favourable safety-relevant properties of the Opalinus Clay and in particular the self-sealing performance. Conversely, laboratory and in situ experiments both demonstrated that the intrinsic permeability even decreased at elevated temperature. In laboratory experiments, a potential permeability decrease remains after cooling. This finding, together with the observation of a thermally induced plastic compaction above $70^{\circ} \mathrm{C}$ (see Figure 3) indicates that the beneficial action of self-sealing will be enhanced by thermal plastification in the damaged zone.

The investigation of a borehole and its damaged zone in the Mont Terri URL (see section 2.4.2) confirms the expected creation process of the excavation damage around galleries parallel to bedding planes in the Opalinus Clay. This understanding opens the way to improve the design with respect to minimising the impact of a connected fracture network around emplacement tunnels and seals. The observed predominance of bedding parallel buckling in the Opalinus Clay suggests that the excavation damage may possibly be mitigated or even reduced by increasing cohesion among bedding planes with the help of the early installation of appropriate support systems. 


\section{Conclusions and remaining issues}

Following the accomplishments of the SELFRAC project devoted to better understand the formation of the excavation damaged zone and the self-sealing of fractures around a geological repository in clay formations, significant progress has been made within the TIMODAZ project regarding the subsequent evolution of the damaged zone during the thermal transient caused by the heat emitted by the waste. Obtained data provided further understanding of the THM coupled processes over the range of temperatures and temperature gradients expected in the near field of a geological repository, and thereby increased the confidence in long-term safety. Most of the results revealed neutral or positive effects of the thermal transient and provided additional safety arguments.

The test results from the TIMODAZ project showed that the impact of elevated temperatures on clay is twofold. On the one hand, at moderate temperatures where only thermoelastic expansion occurs, the micro structure of the clay matrix in bulk clay remains intact and is not negatively affected. On the other hand, thermo-plastic contraction is observed at higher temperature, resulting in a denser clay structure, favourable to radionuclide retention.

There is no evidence throughout the TIMODAZ experimental data of temperatureinduced fracture opening or significant DZ permeability increase with temperature. Moreover, the experiments confirmed that self-sealing was not negatively altered by an increase in temperature. Instead, thermally-induced plasticity, swelling and creep are likely to be beneficial to the sealing of fractures and to the recovery of the DZ permeability back to the initial state. One-year long batch experiments carried out on Boom Clay samples and Opalinus Clay samples at $90^{\circ} \mathrm{C}$ revealed no significant mineralogy changes.

Several TIMODAZ experiments confirmed the anisotropic mechanical and transport properties related to the clay sedimentary origin. Accounting for anisotropic features in numerical models was found to significantly enhance their predictive capabilities. The 
anisotropy in thermal conductivity obviously has an impact on the temperature changes in the host formation and surrounding geology, therefore should be taken into account in the final design of the geological repository. In addition, the structural anisotropy of the clay formation makes fluid (water and gas) and solutes (radionuclides) transport faster along the bedding planes, which are generally sub-horizontal at potential repository locations.

Although the impact of elevated temperatures in clay does not seem to be detrimental to the safety of repository at long term, a few issues remain regarding the evolution of the DZ during the thermal transient. Shortly after excavation, the boundary conditions and stress state in the $\mathrm{DZ}$ are quite different from the initial state. In the near field of the repository, the confining stress may be relatively low and sealed fractures without healing will behave like weak planes. Although no opening of fractures upon heating was found during the TIMODAZ project, reactivation of shear band by thermal pressurization was found in one experiment, even though this did not lead to an increase of permeability. Reopening of pre-existing cracks was triggered by shearing under low mean stress in another experiment, resulting in a significant permeability increase. These experiments suggest that modelling at the scale and with the boundary conditions of a repository should be done on a case by case basis to check whether fracture reactivation should be expected in practice. Large-scale heater tests about to start in HADES at Mol and in the Mont Terri underground laboratory are also expected to provide further insights at repository-relevant scale.

For the sake of completeness, it should be mentioned that an extensive assessment of the thermal impact on the geochemically disturbed zone (perturbations in the near field such as oxidation and the alkaline plume) was beyond the scope of the TIMODAZ project. Hence, some uncertainties do remain about the long-term effects on radionuclide retention processes within the DZ when undergoing simultaneously the thermal transient and geochemical perturbations. In 
the case of Boom Clay, consequences of the significant presence of dissolved and insoluble relatively immature organic matter remain to be assessed adequately.

In summary, results from the TIMODAZ project strongly suggest that the heat emitted from the waste packages in a geological repository designed according to the current reference concepts (Bel et al. 2005; NAGRA 2002a \& 2002b) should have no detrimental effects on the barrier functions of the clay host rock in the damaged zone. The favourable physical properties of the clay that guarantee the effectiveness of the safety functions of the repository system are expected to be maintained after the heating-cooling cycle. The basic assumptions currently used in PA to represent the EDZ in the calculations remain justified when considering the thermal evolution of radioactive waste repositories in clay formations.

As a consequence, the results of the TIMODAZ project strengthen the SELFRAC conclusion that the (E)DZ should not be considered as a critical issue in the long-term safety of radioactive waste repositories in clay formations after the heating-cooling cycle. Remaining uncertainties, such as long time-scales, chemical perturbations, gas production in the system and further characterisations of the clay anisotropy, can be partly addressed by valorising the experimental equipments and procedures developed during the project, and by focussing the modelling efforts on upscaling laboratory results in both spatial and temporal scales. Upcoming large-scale in situ heater tests may provide opportunities to test the upscaled models at least with respect to the spatial scale and will in any case enhance the scientific basis on which safety cases can be built.

\section{Acknowledgements}

This work was funded by the European Commission through the TIMODAZ project within the $6^{\text {th }}$ framework programme (Contract Number: FI6W-CT-2007-036449). The part of the work performed by $\mathrm{SCK} \cdot \mathrm{CEN}$ and EURIDICE also benefited from co-funding by the Belgian agency for radioactive waste management (ONDRAF/NIRAS). All the experimental and numerical 
results presented in this paper were obtained within the frame of the TIMODAZ project. The authors express their sincere gratitude for the enthusiastic, sharing and collaborative R\&D spirit displayed by all TIMODAZ partners. 


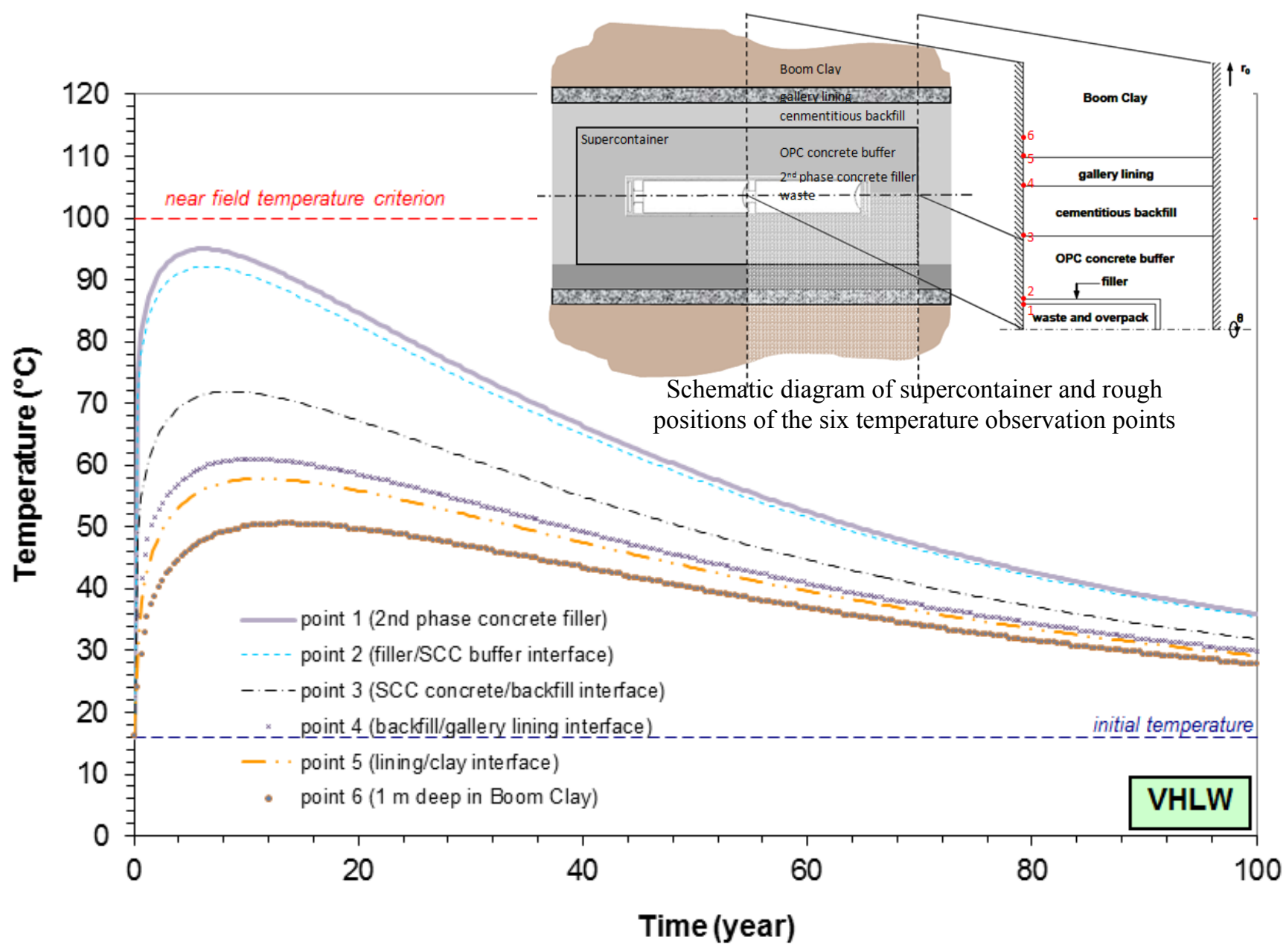

Figure 1: Temperature evolution at different locations in the near field of a supercontainer-based repository filled with VHLW (cooling time of 60 years, thermal conductivity of the Boom Clay is $1.45 \mathrm{~W} /(\mathrm{mK})$ ) (Weetjens 2009 ) 


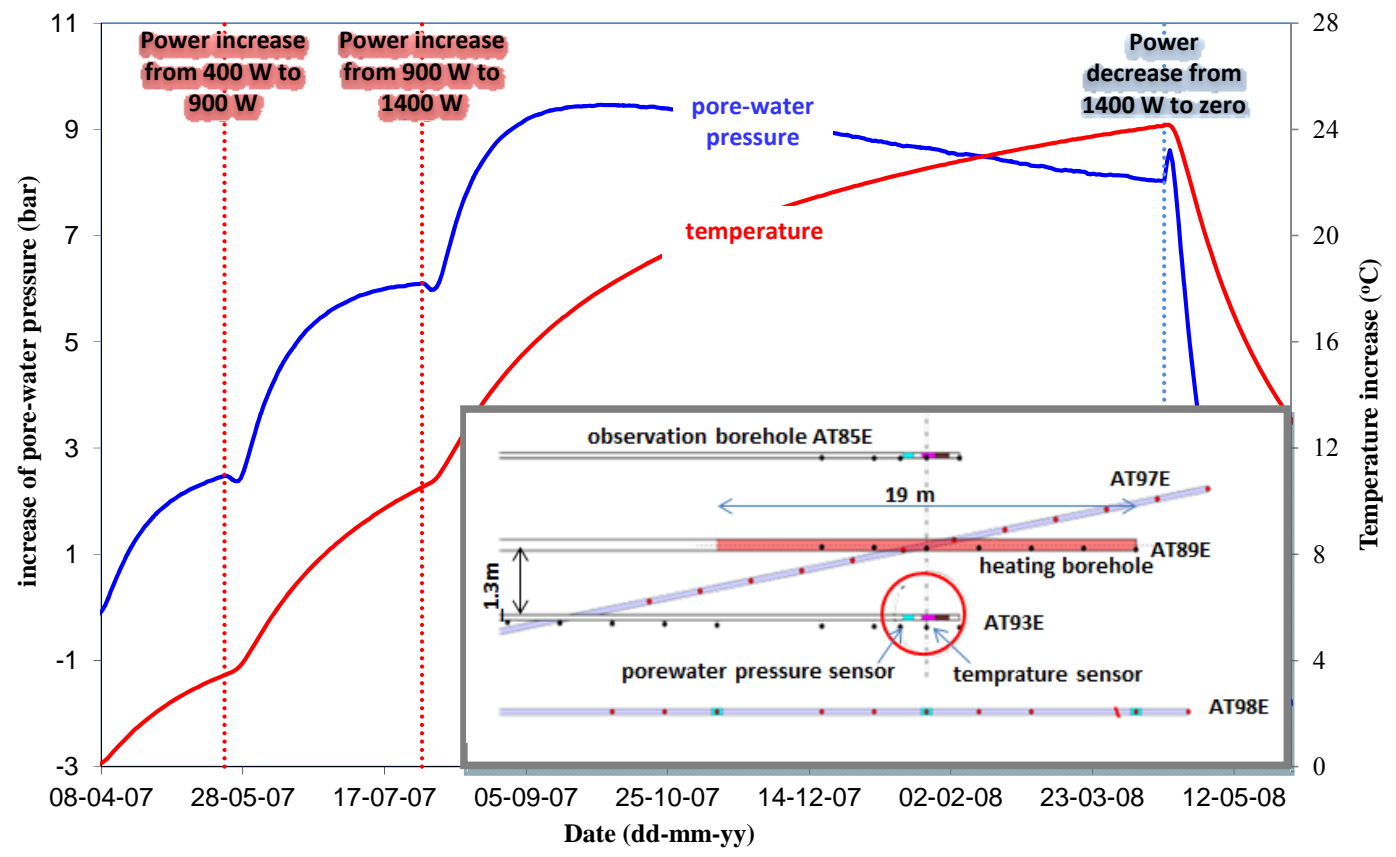

Figure 2: Measurements of pore water pressure and temperature in the borehole AT93E from in situ heater test ATLAS III at HADES URF (distance between pore water pressure sensor and temperature sensor is $40 \mathrm{~cm}$ ) (Chen et al. 2011) 


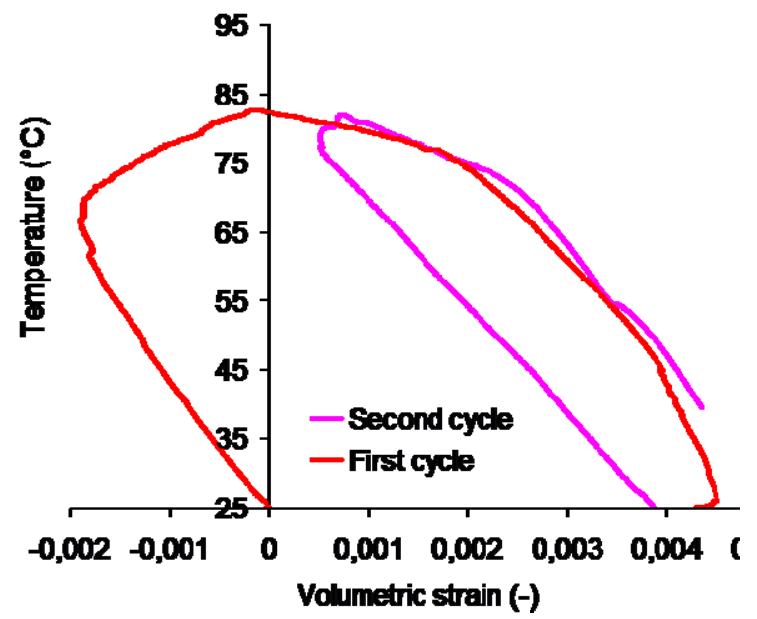

Figure 3: Drained heating test on Opalinus clay under in situ stress (Monfared et al. 2012a) 

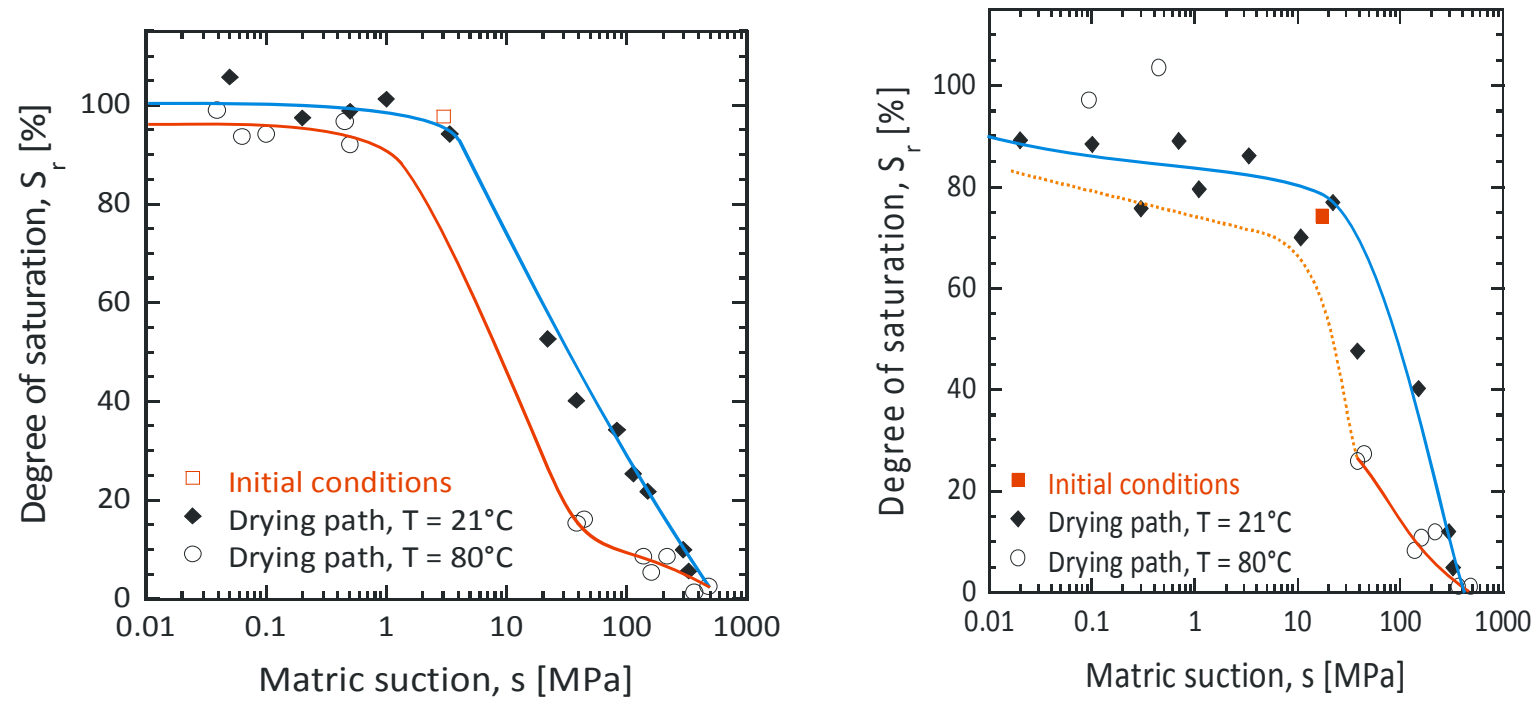

Figure 4: Water retention curves of the Boom Clay (left) and the Opalinus Clay (right) at two different temperatures (Rizzi 2012; Laloui et al. 2012) 


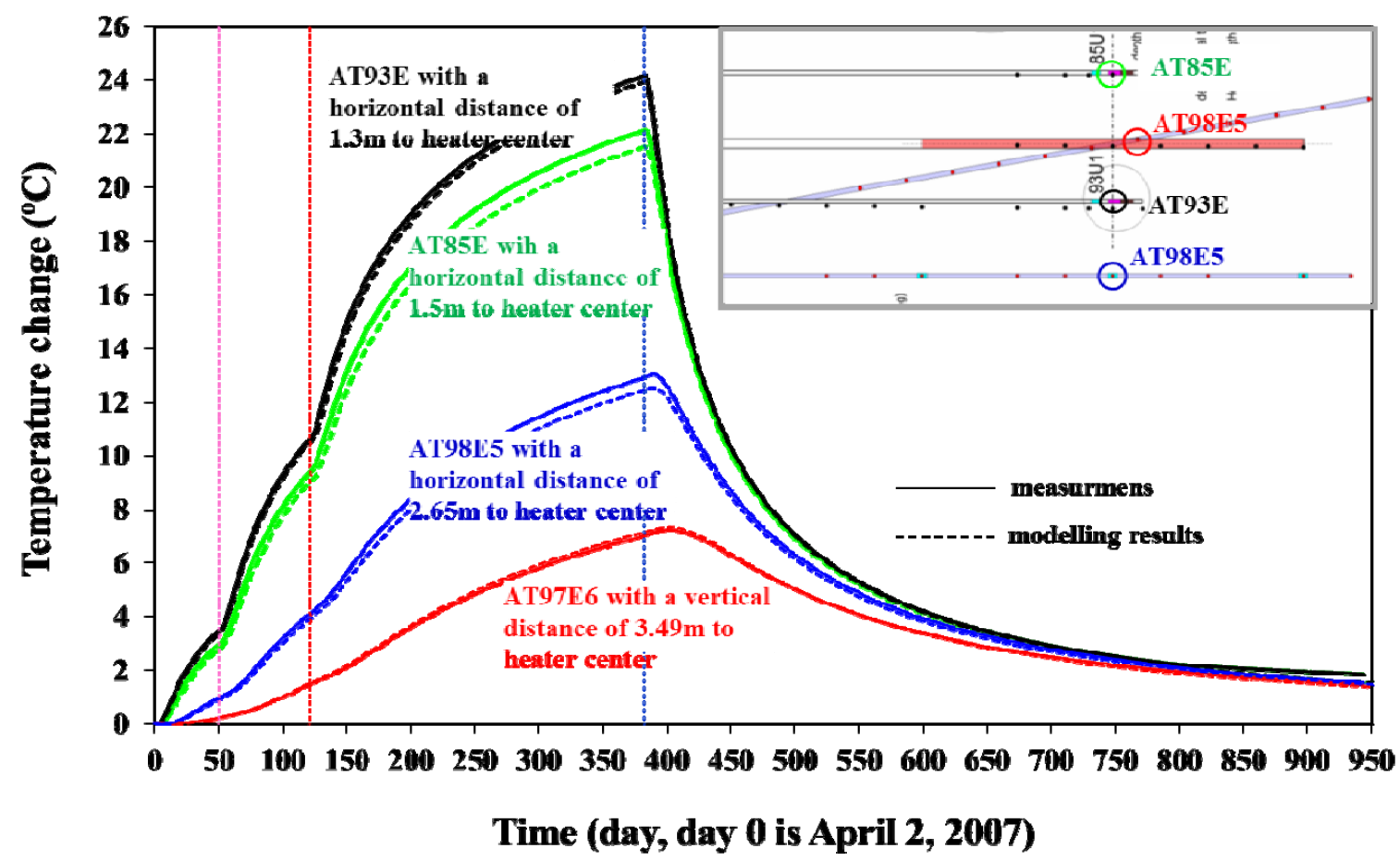

Figure 5: Temperature response from in situ small-scale heater test ATLAS III at HADES URL: sensor in the direction parallel to the bedding plane (AT93E,AT85E and AT98E5) and in perpendicular direction (AT97E6) (Chen et al. 2011). 


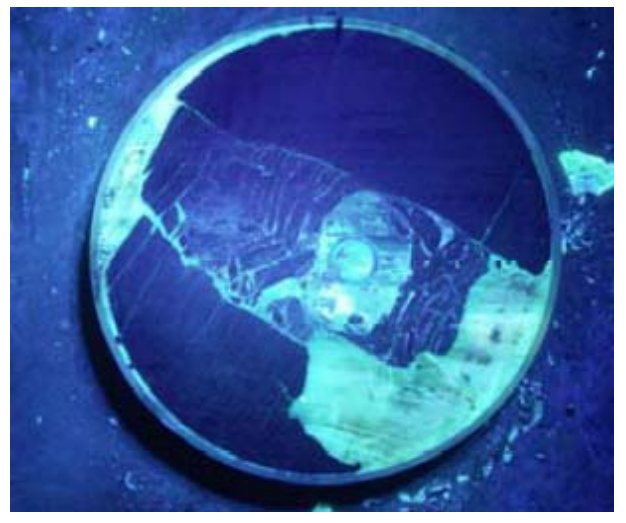

(a)

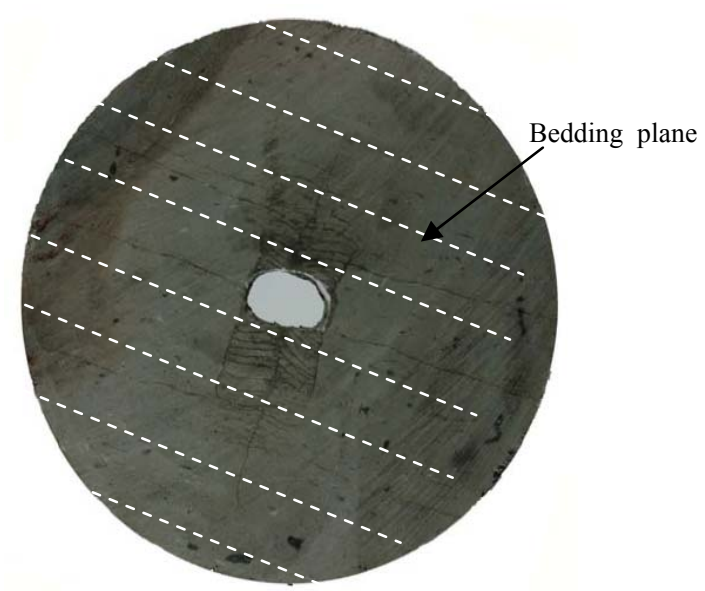

(c)

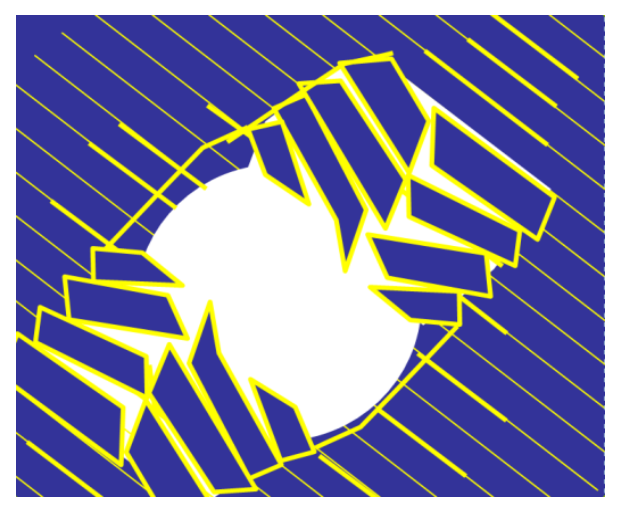

(b)

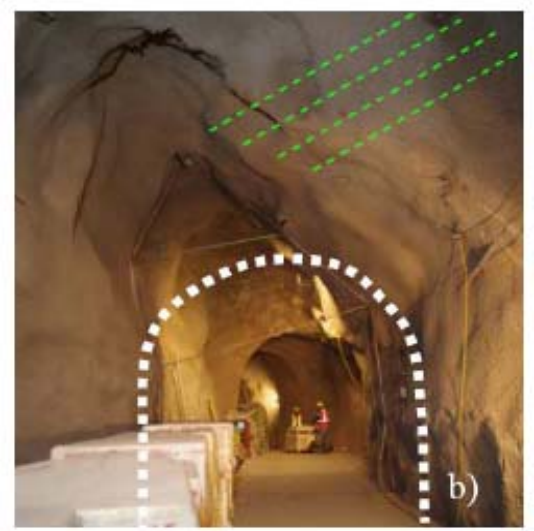

(d)

Figure 6: Similar fracture pattern observed in Opalinus clay in the (a) in situ test at Mont Terri URL (b) )A sketch of the borehole collapse structure (c) hollow cylinder test $\mathrm{N}^{\circ} 12$ (Labiouse and Vietor 2013) (d) formerly horseshoe type tunnel. 

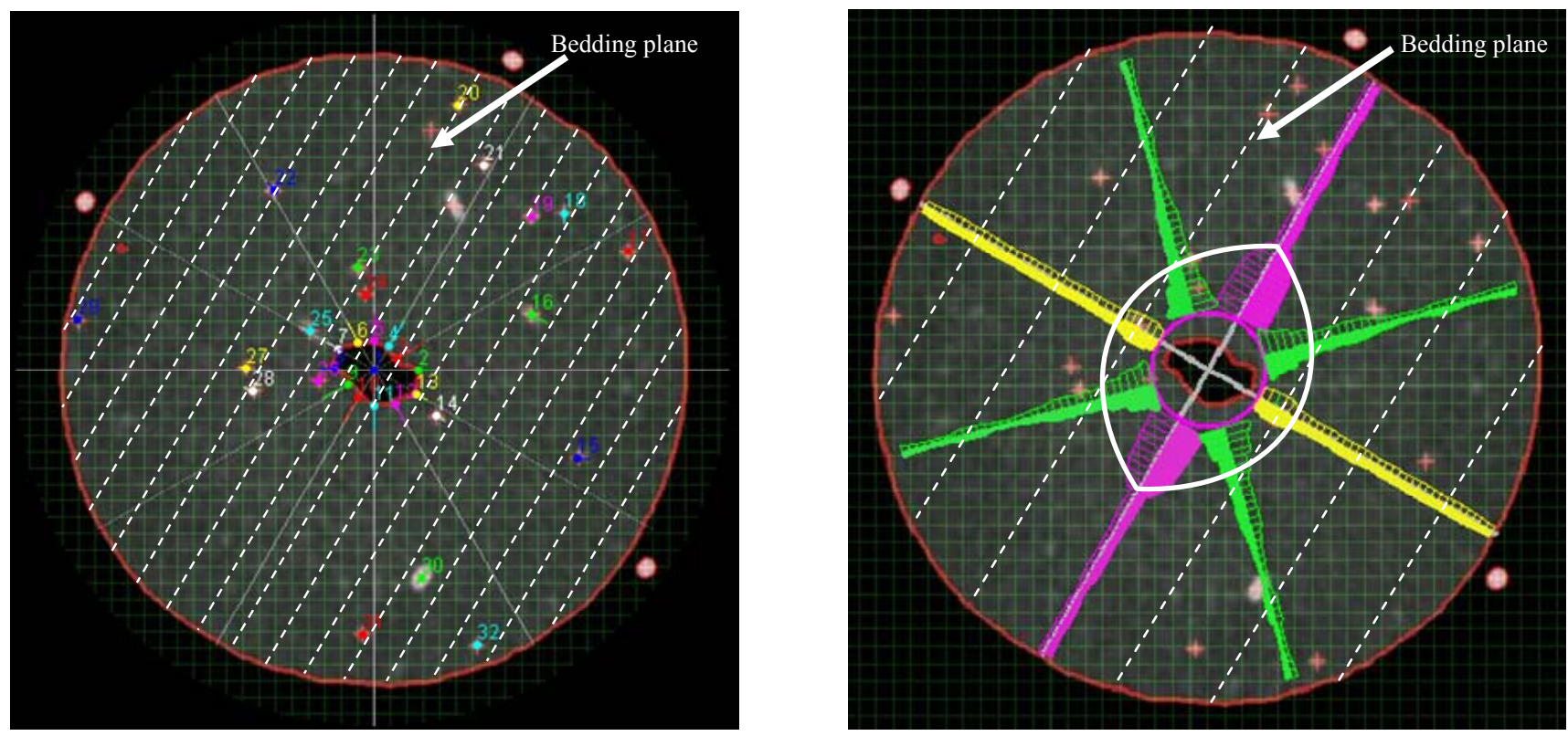

(a)

(b)

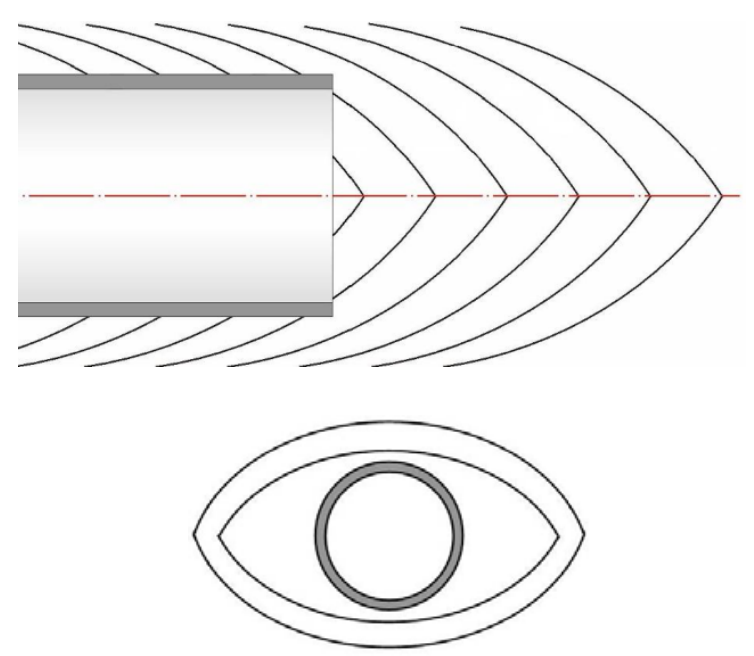

section view

(c)

Figure 7: Observed behaviour around openings in Boom Clay: (a) CT scan of the hollow cylinder sample 13A after mechanical unloading (b) profile of total displacement parallel, perpendicular and at $45^{\circ}$ to the bedding obtained by tracking pyrite inclusions in the scans before and after mechanical unloading (Labiouse et al. 2013) and (c) sketch of the excavation induced fracture pattern at HADES URL 


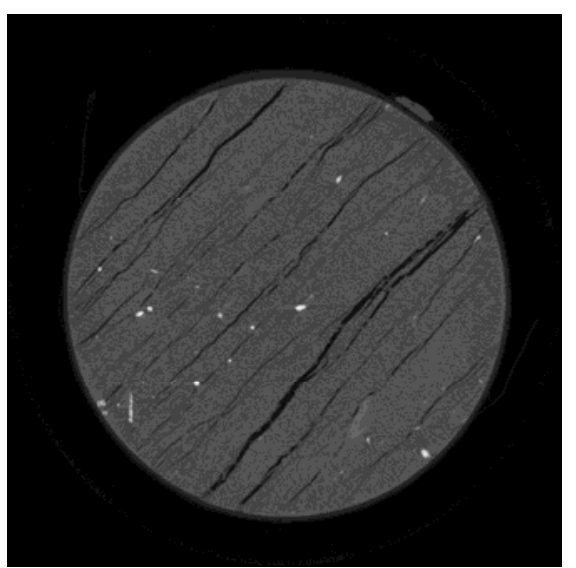

Figure 8: Multiple parallel fissures opening along bedding planes as revealed by a XRCT of an Opalinus clay specimen before testing (Viggiani and Bésuelle 2012) 


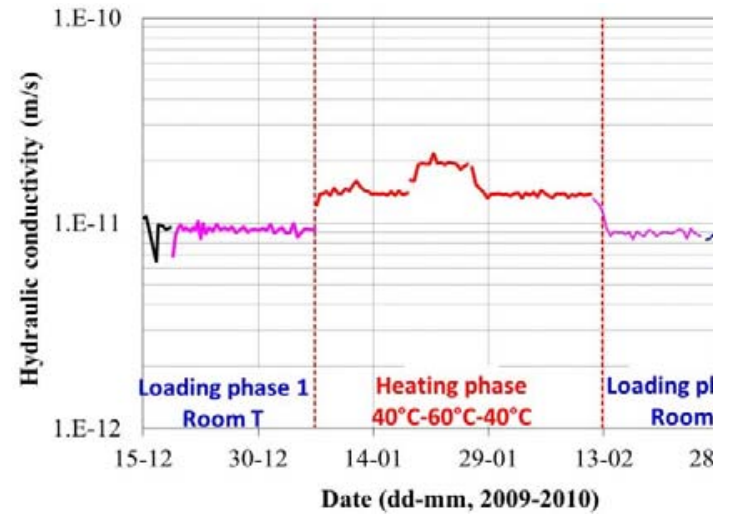

(a)

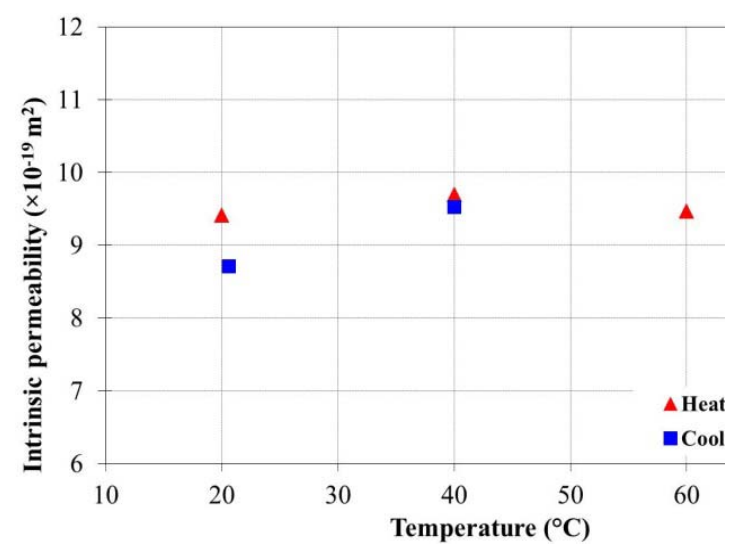

(b)

Figure 9: Variation of (a) hydraulic conductivity with time (b) intrinsic permeability with temperature under constant confining pressure conditions for the Boom Clay in isostatic test (Chen et al. 2013) 


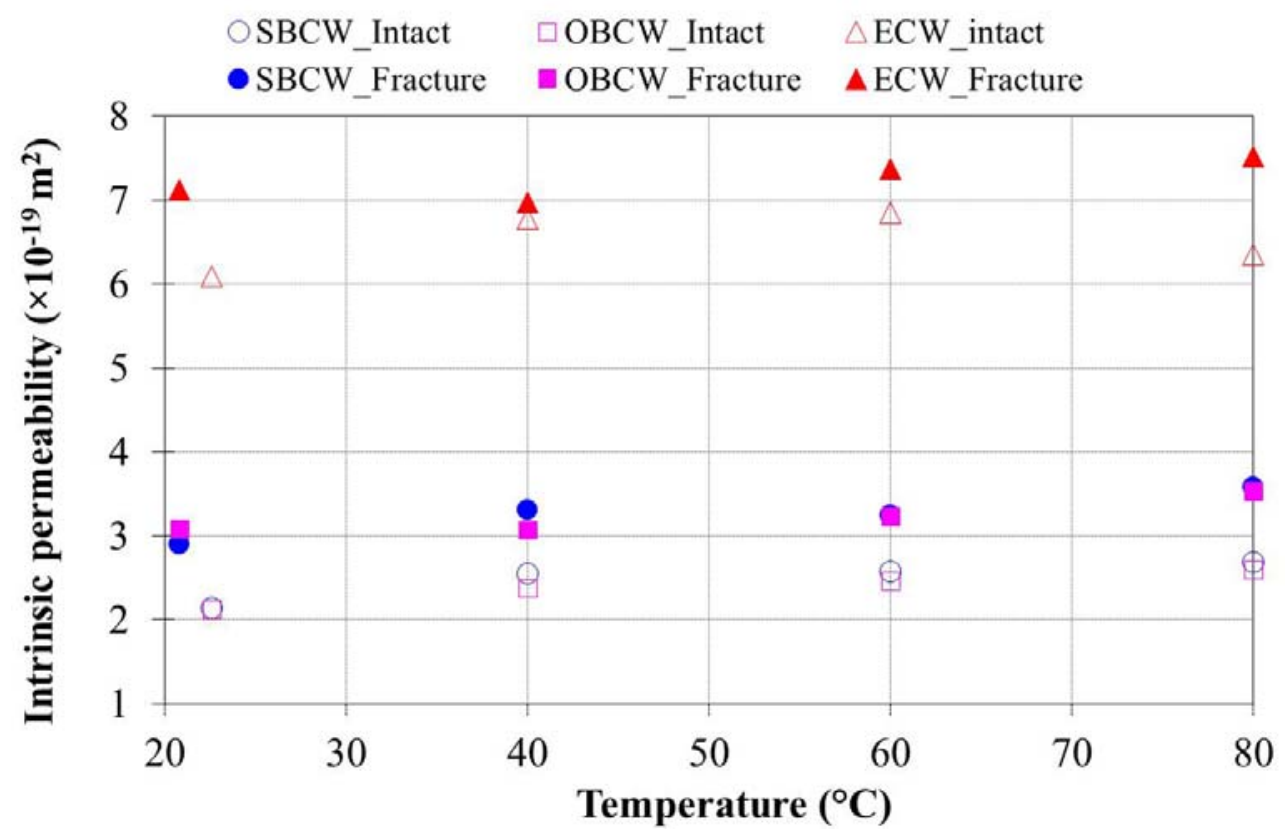

(a) Boom Clay (hollow symbols for intact samples, solid symbols for fractured samples) (SBCW for synthetic Boom Clay water, OBCW for oxidized Boom Clay water and ECW for evolved cement water)

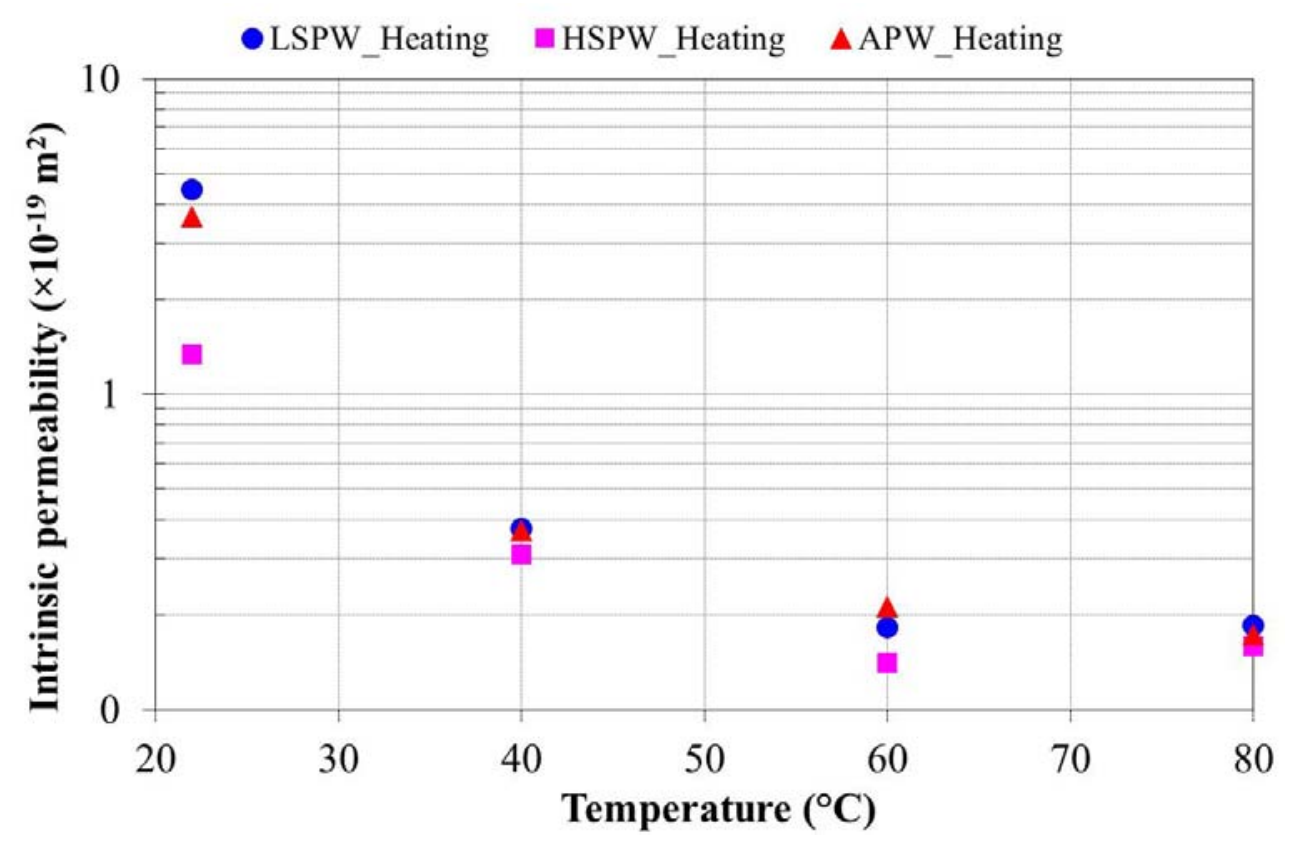

(b) Opalinus Clay with artificial fractures (LSPW for low salinity pearson water, HSPW for high salinity pearson water and APW for alkaline pearson water)

Figure 10: Variations of intrinsic permeability with temperature for the Boom Clay (above) and Opalinus

Clay (below) in permeameter tests with fixed volume (Chen et al. 2013). 


\section{References}

Baldi G, Hueckel T, Peano A, Pellegrini R (1991) Developments in modelling of thermo-hydrogeomechanical behaviour of Boom clay and clay-based buffer materials (vol. 2). Commission of the European Communities, Nuclear Science and Technology, EUR $13365 / 2$

Bastiaens W and Demarche M (2003) The extension of the URF HADES: realization and observations. WM'03 conference, Feb. 23-27, 2003, Tucson, AZ

Bastiaens W, Van Cotthem A, Voorspoels T (2008) Design and realisation of the PRACLAY experimental gallery. Congrès international de Monaco, 223-230

Bel I, Van Cotthem A, De Bock C (2005) Construction, Operation and Closure of the Belgian Repository for Long-Lived Radioactive Waste. Proceedings of ICEM'05: The $10^{\text {th }}$ International Conference on Environmental Remediation and Radioactive Waste management, September 4-8, 2005, Scottish Exhibition \& Conference Centre, Glasgow, Scotland

Bernier F, Li XL, Bastiaens W et al (2006) SELFRAC: Fractures And Self-Healing Within The Excavation Disturbed Zone In Clays - Final technical report, Luxembourg, European Commission

Blümling P, Bernier F, Lebon P, Martin CD (2007) The Excavation-Damaged Zone in Clay Formations - Time-dependent Behaviour and Influence on Performance Assessment. Phys Chem Earth 32(5-14): 588-599

Bruggemanm C, Aertsens M, Maes N, Salah S (2010) Iodine retention and migration behaviour in Boom clay. External report of Belgian Nuclear Research Centre, SCK·CEN-ER-119

Charlier R (eds) (2010) Simulation of lab and in situ test. TIMODAZ Deliverable 13

Chen GJ, Sillen X, Verstricht J, Li XL (2011) ATLAS III In Situ Heating Test in Boom clay: Field data, observation and interpretation. Computers and Geotechnics 38(5): 683-696

Chen GJ, Maes T, Vandervoort F, Xavier S, Van Marcke P, Honty M, Dierick M, Vanderniepen P (2013) Thermal impact on damaged Boom Clay and Opalinus Clay: Permeameter and Isostatic tests with mCT scanning. Rock Mech Rock Eng. doi: 10.1007/s00603-0120334-y

Croisé J, Schlickenrieder L, Marschall P, Boisson JY, Vogel P, Yamamoto S (2004) Hydrogeological investigations in a low permeability claystone formation: the Mont Terri Rock Laboratory. Physics and Chemistry of the Earth 29(1): 3-15

De Cannière P, Moors H, Lolivier P, De Preter P, Put M (1996) Laboratory and in situ migration experiments in the Boom clay. European Commission Nuclear Science and Technology report EUR 16927 EN, Luxembourg: European Commission

Delage P, Sultan N, Cui YJ (2000) On the thermal consolidation of Boom clay. Canadian Geotechnical Journal 37 (2): 343-354

Delage P (eds) (2010) THM characterisation and input for simulation, TIMODAZ Deliverable 5.

Delage P, Cui YJ, Tang AM (2010) Clays in radioactive waste disposal. Journal of Rock Mechanics and Geotechnical Engineering 2(2): 111-123 
François B, Labiouse V, Dizier A, Marinelli F, Charlier R, Collin F (2013) Hollow cylinder tests on Boom Clay: modelling of strain localization in the anisotropic Excavated Damaged Zone. Rock Mech Rock Eng. doi: 10.1007/s00603-012-0348-5

Garitte B, Sillen X, Li XL, Armand G, Vaunat J and Gens A (2009) Comparative study of three in-situ heating tests in anisotropic media: the HE-D, TER and ATLAS experiments, proceedings of the EC-TIMODAZ-THERESA THMC conference, Luxembourg

Honty M, Wang L, Osacký M, Uhlík P, Czímerová A, Madejová J (2012) Experimental interactions of the Opalinus Clay and Boom Clay with various repository relevant solutions at $90{ }^{\circ} \mathrm{C}$ under closed conditions. Applied Clay Science 59-60: 50-63

IAEA (2006) International Atomic Energy Agency: Geological disposal of Radioactive Waste. Safety Requirements. IAEA Safety Standards Series No. WS-R-4, Vienna, 2006

Labiouse V, Escoffier S, Gastaldo L, Mathier JF (2009) Self-Sealing of Localised Cracks in Boom and Opalinus Clay Hollow Cylinders, proceedings of the EC-TIMODAZTHERESA THMC conference, Luxembourg, 29 Sep -1 Oct. EUR 25527 EN, pp 379383.

Labiouse V, Sauthier C, You S (2013) Hollow cylinder simulation experiments of galleries in Boom Clay formation. Rock Mech Rock Eng. doi: 10.1007/s00603-012-0332-0

Labiouse V and Vietor T (2013) Laboratory and in situ simulation tests of the Excavation Damaged Zone around galleries in Opalinus Clay. Rock Mech Rock Eng. doi: 10.1007/s00603-013-0389-4

Laloui L, Salager S, Rizzi M (submitted to Acta Geotechnica) Characterization of Water Retention Behaviour of soils at different temperatures.

Mazurek M, Pearson FJ, Volckaert G, Bock H (2003) Features, Events and Processes Evaluation Catalogue for Argillaceous Media. Nuclear Energy Agency Organization for Economic co-Operation and Development

Mohajerani M, Delage P, Sulem J, Monfared M, Tang AM, Gatmiri B (2012) A laboratory investigation of thermally induced pore pressures in the Callovo-Oxfordian Claystone. International Journal of Rock Mechanics and Mining Sciences 52: 112-121

Monfared M, Delage P, Sulem J, Mohajerani M, Tang AM, De Laure E (2011) A new hollow cylinder triaxal cell to study the behaviour of low permeable materials. International Journal of Rock Mechanics and Mining Sciences 48 (4): 637-649

Monfared M, Sulem J, Delage P, Mohajerani M (2012a) A laboratory investigation on the thermal properties of the Opalinus claystone. Rock Mechanics and Rock Engineering 44: $735-747$

Monfared M, Sulem J, Delage P, Mohajerani M (2012b) On the THM behaviour of a sheared Boom clay sample: application to the behaviour and sealing properties of the EDZ. Engineering Geology 124: 47-58

NAGRA (2002a) Project Opalinus claylinus Clay: Safety Report. Nagra Technischer Bericht NTB 02-05

NAGRA (2002b) Calculations of the Temperature Evolution of a Repository for Spent Fuel, vitrified high-Level Waste and Intermediate Level Waste in Opalinus Clay. Nagra Technischer Bericht NTB 01-04

NEA (2007) Safety cases for deep geological disposal of radioactive waste: where do we stand? NEA No. 6319, Symposium Proceedings Paris, France, 23-25 January 2007 
ONDRAF/NIRAS (2001) Safety Assessment and Feasibility Interim Report 2 (SAFIR 2). Brussels

ONDRAF/ NIRAS (2008) Impact of a long-term thermal stress on an aquifer. NOCA 2008-0118

ONDRAF/NIRAS (2009a) The plan for the Safety and Feasibility Case 1, ONDRAF/NIRAS report NIROND-TR 2009-13E

ONDRAF/NIRAS (2009b) The long-term safety assessment methodology for the geological disposal of radioactive waste. ONDRAF/NIRAS report NIROND-TR 2009-14E

ONDRAF/NIRAS (2009c) The long-term safety strategy for the geological disposal of radioactive waste, ONDRAF/NIRAS report NIROND-TR 2009-12E

Picard JM and Giraud A (1995). Application of thermoporomechanics to problems of storage of radioactive waste, Mechanics of Porous Media, Charlez (ed). Balkema, Rotterdam

Rizzi M (2013) Analysis of the thermo-hydro-mechanical behaviour of bentonite. PhD dissertation, Swiss Federal Institute of Technology, EPFL.

Sultan N (1997) Etude du comportement Thermal-HydroMéchanique de l'argile de Boom expérimentation et modélisation. PhD thesis, École Nationale des Ponts et Chaussées, Paris

Sultan N, Delage P, Cui YJ (2000) Comportement thermomécanique de l'argile de Boom. Comptes-Rendus de l'Académie des Sciences, Série II B-Mécanique 328(6) : 457-463

Sultan N, Delage P, Cui YJ (2002) Temperature effects on the volume change behaviour of Boom clay. Engineering Geology 64(2-3): 135-145

Van Geet M, De Craen M, Beerten K, Leterme B, Mallants D, Wouters L, Cool W, Brassinnes S (2012) Climate evolution in the long-term assessment of surface and geological disposal facilities for radioactive waste in Belgium. Geologica Belgica 15 (1-2): 8-15

Van Marcke P and Bastiaens W (2010) Excavation induced fractures in a plastic clay formation: Observations at the HADES URF. J Struct Geol 32: 1677-1684

Vietor T, Li XL, Chen GJ, Verstricht J, Fisch H, Fierz T (2010) Small scale in-situ tests: Borehole experiments at HADES and Mont Terri rock laboratories, TIMODAZ Deliverable 8

Viggiani G and Bésuelle P (2012) personnel communication.

Weetjens E (2009) Update of the near field temperature evolution calculations for disposal of UNE-55, MOX-50 and vitrified HLW in a supercontainer-based geological repository. External report of Belgian Nuclear Research Centre, SCK·CEN-ER-86

Yu L, Rogiers B, Gedeon M, Marivoet J, De Craen M, Mallants (2013) A critical review of laboratory and in-situ hydraulic conductivity measurements for the Boom Clay in Belgium. Applied Clay Sciences. http://dx.doi.org/10.1016/j.clay.2013.02.018 